current conceptions-he does not, for example, accept the view that house dust extract is an entity which differs from the sum of its components, as Professor Rimington's recent work appears to show. He also makes more use of vaccines, particularly those prepared from stool cultures, than most modern bacteriologists would approve.

$\mathrm{He}$ is rightly critical of the mis-use of such wellknown terms as ' allergy,' 'immunity,' ' atopy' and 'psychological'; in an attempt to achieve precision of meaning he has invented a terminology of his own, including 'toxic idiopathy,' ' idiotoxin,' 'pathophane' and 'phylactology.' Although in some cases these terms were actually fathered by Sir Almroth Wright himself, in the reviewer's opinion their use now only serves to make a difficult subject more confusing.

In spite of these minor criticisms the book can be strongly recommended to all who are interested in this important group of diseases. It is an important contribution to the study of allergy presented in an original manner. Messrs. Heinemann are also to be congratulated on its production.,

R.S.B.P.

\section{EPIDEMICS IN SCHOOLS}

\section{An Analysis of the Data collected during the Years r935-1939}

By E. A. Cheeseman, Ph.D., B.Sc. Medical Research Council Special Report Series No. 271. Pp. vii + 96. 3s. London: H.M.S.O. 1950.

The two objects of this survey and of its forerunner (Special Reports Series No. 227) were (a) to collect facts regarding illnesses in schools and (b) to see whether the lessons learnt about experimental laboratory epidemics could be applied to human communities. At first sight, the 'closed' nature of the boarding school community might appear to approximate to the laboratory herd but there are several important differences-the varied bacteriological experience of the members and the breaking-up of the 'herd' at the end of each term are the most obvious. Not unexpectedly then, it was found that infections did not always behave in a mathematical manner; there was, for example, no specific critical proportion of susceptibles necessary for the spread of disease after the introduction of infection, although this factor might well affect the course of the outbreak.

As the report admits, no epidemiological problems have been solved by the investigation but its first aim, the collection of facts, has certainly been achieved. From these facts at least one important deduction has been made, namely that the apparently higher rate of nasopharyngeal infection in girls' schools may in reality be only the result of the greater care given to minor illnesses in girls' schools. This high incidence is, however, offset by a lower rate of serious complications and the suggestion is made that the two are related, the greater care leading to an apparently higher rate of minor illnesses, but also to the lower rate of serious complications. This would appear to be a valid deduction from the figures, and although it does no more than confirm that prevention is better than cure, it might well be studied carefully by medical officers to boys' schools. Apart from this one observation, most of the statistics tend only to establish on a factual basis the epidemic picture that one might somewhat vaguely have visualized on general epidemiological principles.

\section{CONGENITAL HEART DISEASE}

By J. W. Brown, M.D., F.R.C.P. 2nd Edition. Pp. xiii + 344, with r 28 illustrations. London: Staples Press. 1950. 30s.

In the second edition of this monograph on congenital heart disease the general arrangement of the book is unchanged, but a large part of the text has been re-written to include many of the advances in diagnosis and treatment made in the I I years which have elapsed since the first edition. The description of the embryological, pathological and clinical changes in the various malformations are good, and are well illustrated by numerous diagrams, $X$-ray plates and photographs of pathological specimens. The literature on the subject has been well covered and a notable feature is the excellent bibliography. The importance of making a correct diagnosis of the exact nature of the congenital malformatiom has been emphasized by recent developments in surgical treatment. Although, as the author has shown, valuable information can be gained by routine methods of clinical and radiological examination, special methods of investigation such as angiocardiography are often helpful, and if operation is contemplated they are essential. For this reason it is disappointing to find that the book contains no adequate account of the use of either angiocardiography, cardiac catheterization or modern electrocardiography in the study of congenital heart disease. Apart from this omission, which will doubtless be corrected in a subsequent edition, this book provides probably the best account of the subject which is available today and it is a valuable addition to cardiological literature.

\section{INDUSTRIAL LUNG DISEASES OF IRON ÀND STEEL FOUNDRY WORKERS}

By A. I. G. McLaughlin, M.B., Ch.M., F.R.C.P., et al. -Pp. xiv +282 , with 49 illustrations and 5 I chest radiographs. London: H.M.S.O. 1950. fir Is. od.

This report from the Factory Department, Ministry of Labour and National Service, presents the findings of a team of investigators into the problem of industrial lung disease as it occurs among iron and steel foundry workers in Great Britain.

The opening chapters provide an excellent review of the relevant world literature and a comprehensive description of foundry processes. A brief general outline of the industry, production and 